DOI: $10.20287 /$ doc.d20.ac2

\title{
O documentário Benzedeiras: ofício tradicional como uma forma de retratar a cultura popular e os ofícios tradicionais
}

\author{
Fabiane Führ*
}

\author{
Benzedeiras: ofício tradicional (Brasil, 2015, 24 min.) \\ Roteiro e Direção: Lia Marchi \\ Direção de Produção: LM Stein \\ Entrevistas: Agda de Andrade Cavalheiro, Eugenia Ferreira de Deus, Donatila \\ Ferreira Kuller, Ana Maria dos Santos e Antonio Michel Kuller Meira \\ Produção Executiva: Marinardes Marchi \\ Assistente de Produção: Ângela Oskar \\ Fotografia: Bruno Ravagnolli \\ Som: Maria Clara Cervantes \\ Logger: Nilton Felicio \\ Montagem: Silvia Hayashi \\ Edição de Som e Mixagem: Luiz Adelmo, ABC \\ Colorista: Mario Cassettari \\ Design Gráfico: Adalberto Camargo
}

\section{Introdução}

A proposta da diretora Lia Marchi com o documentário Benzedeiras: oficio tradicional (2015), é mostrar o trabalho de benzedeiras e benzedores que vivem em cidades do interior do Paraná e relatar os desafios e dificuldades enfrentadas pelos detentores deste ofício.

O filme retrata a história de benzedeiras que residem nas cidades de Rebouças e São João do Triunfo. O projeto do filme teve início em 2011, quando Lia Marchi, a cineasta, compareceu a um encontro promovido pelo Instituto do Patrimônio Histórico e Artístico Nacional (Iphan), na capital do estado do Paraná, organizado para receber o grupo de benzedeiras e curadores. Depois disso, várias viagens foram realizadas pela cineasta e sua equipe para conhecer e registrar a história desses homens e mulheres.

\footnotetext{
* Mestranda, Universidade Tuiuti do Paraná (UTP), Programa de Pós-Graduação em Comunicação e Linguagens, Estudos de Cinema e Audiovisual. 83.602-760, Campo Largo, Brasil. E-mail: fabifuhr@gmail.com
} 
Em entrevista concedida pela cineasta para a TV Evangelizar, na qual o documentário é o tema principal, a cineasta explica que o filme fala

[...] da organização popular, ele fala da sustentabilidade, fala da fé, fala da questão da saúde muito, fala dos movimentos das mulheres, mas principalmente eu acho que ele é um filme de afeto. Ele é um filme de carinho. Essas mulheres estão ali para ajudar o seu próximo e o lema delas 'é cuidar da vida é a nossa missão' e elas passam exatamente isso, né. Esse comprometimento com o ajudar, com o dar sem estar preocupado em receber. E isso conquista, eu acho, realmente, o espectador. (sic) (Marchi, 2015).

\section{Benzedeiras, o documentário}

Lia Marchi busca, através do documentário Benzedeiras: ofício tradicional (2015), disseminar os conhecimentos, técnicas e realidades do cotidiano das benzedeiras a fim de registrar e manter viva a cultura deste grupo de pessoas. A cineasta enfatiza

Em tempos, quando, realmente, o interior não tinha o acesso a um médico, a um hospital elas salvaram muitas vidas. A partir desses conhecimentos. Eu acho que hoje que já tem um médico, felizmente, as comunidades já podem usufruir dos avanços da medicina, as próprias benzedeiras dizem que tem doença que o remédio natural não cura, que é preciso procurar um médico. Mas, ao mesmo tempo, acho que elas ajudam muito a saúde pública, porque às vezes o que as pessoas estão precisando são coisas que uma benzedeira pode realmente ajudar, a inclusive fluir melhor o grande fluxo de atendimento que os hospitais tem hoje. (sic) (Marchi, 2015).

O documentário começa mostrando uma benzedura. Na Figura 1 é possível observar que Dona Agda utiliza um ramo de algum tipo de erva medicinal, para auxiliá-la neste ritual.

Figura 1 e 2. Dona Agda, realizando a benzedura e enquanto debulha o milho

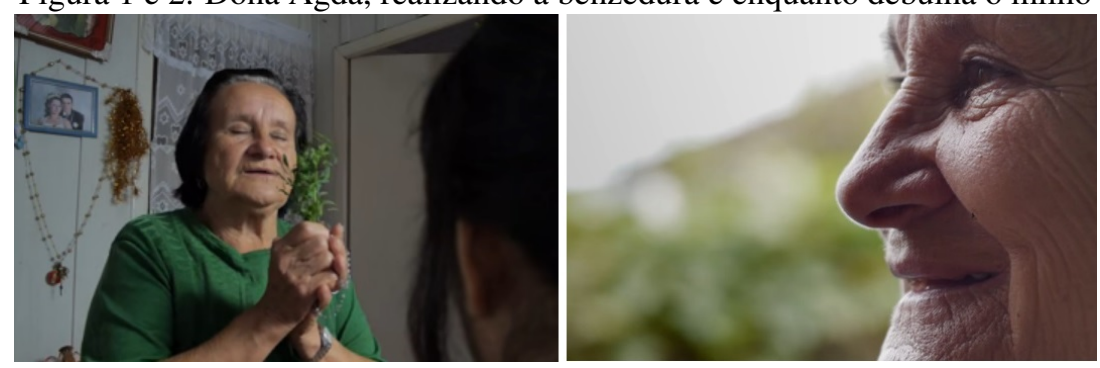

Fonte: Frame capturado do documentário Benzedeiras: ofício tradicional

Na sequência, Dona Agda, a benzedeira, é retratada em sua a rotina de cuidados com a horta, colhendo chuchu, bergamotas, flores, capinando e em 
um momento de pausa, no qual ela se apoia sobre a enxada, a tranquilidade do lugar toma a tela e pode-se ouvir o canto dos pássaros, ao fundo. Enquanto Dona Agda debulha o milho, a câmera mostra os detalhes de suas mãos e dá um close em seu rosto (Figura 2). Todo o percurso feito pela câmera é acompanhado do relato dessa benzedeira que recorda a época em que o trabalho era muito mais difícil e pesado. Segundo ela, hoje as atividades são leves. Além disso, Dona Agda diz que o ato de debulhar o milho a faz lembrar uma época em que a produção de biju alimentava toda família.

Ao levar a lenha que será utilizada no fogão para dentro de casa reforça-se o dia-a-dia das cidades interioranas, nas quais a maioria dos moradores cozinha utilizando o fogão a lenha. Dessa forma, todas as cenas são introduzidas com a finalidade de trazer à tona informações sobre o grupo de benzedeiras e curadores, bem como os costumes e hábitos dos habitantes daquele lugar.

A soma das qualidades apresentadas sobre Dona Agda e as demais benzedeiras nos permitem uma série de interpretações que aumentam nossa compreensão em relação ao documentário Benzedeiras.

Com base nesta explicação, compreende-se a necessidade da documentarista nos apresentar pequenos detalhes dessa vida simples que se vive no interior, onde não há a correria dos grandes centros, bem como não há hospitais e outros recursos com os quais os moradores de regiões mais desenvolvidas estão acostumados, o que em parte justifica a importância deste ofício nessas regiões.

Mas o que se entende por ofício tradicional? O que determina que alguém seja mestre em determinado ofício? Segundo Jerusa Pires Ferreira (1996: 103) "o mestre de um ofício é sempre um sabedor, é alguém bastante diferenciado que encarna um semideus, um pactuante com o sobrenatural, um detentor de um tipo de liderança, sobretudo por ser aquele que transforma [...]". A busca pelo reconhecimento do ofício de benzedeiras, curadores e costureiras de machucaduras teve início em 2008. Com o apoio do Movimento Aprendizes da Sabedoria foram mapeados, a partir daquele ano, 294 (duzentos e noventa e quatro) detentores de ofícios tradicionais de cura na região. Com base neste estudo, a Câmara Municipal de Rebouças aprovou, em 2010, a Lei n.1.401/2010 que reconhece os conhecimentos das benzedeiras como oficio tradicional de saúde popular. A regulamentação da lei deu a este grupo o reconhecimento em relação aos conhecimentos relacionados à saúde pública e garantindo que possam exercer e coletar plantas medicinais nativas livremente (Paraná Shop, 2015).

Dona Agda, enquanto pedala sua antiga máquina de costura, relata: 
No tempo do meu avô e do meu pai, médico era só em Curitiba. Por aqui nos interior nunca tinha médico. Quando ficavam doente, que ficavam muito mal, levavam para Curitiba... Pra cá não existia médico, era só farmacêutico e os bocaiero, que eles diziam que era os benzedor de remédio do mato. Os farmacêutico já davam remédio da farmácia e os benzedor, que diziam os bocaiero iam lá pro mato juntá aquelas bocozada, que vinham na sacola cheia de pasto, raiz, cipó, folha para ensina pras pessoa fazerem o banho, fazerem o chá e a esfregação de pomadas que é preparado daqueles remédio. Eu também faço as pomadinha de ervas, tira a dor (sic).

O relato de Dona Agda nos revela o distanciamento existente entre a cultura da elite e a cultura popular, para José Luiz dos Santos (1987: 46) "a cultura popular tem que ser encarada não como uma criação das instituições dominantes, mas como um universo de saber em si mesmo constituído, uma realidade que não depende de formas externas, ainda que se opondo a elas". E corrobora com o que já é sabido: não havia e, em algumas localidades do interior do Brasil, ainda não há, médicos e hospitais. Constata-se isso por meio da enorme quantidade de pessoas que se deslocam diariamente a fim de receber atendimento nos hospitais dos grandes centros e isso acontece apenas porque $\mathrm{o}$ atendimento especializado inexiste próximo de suas residências.

Os estudos de Benatte, Campigoto e Nascimento (2013) relatam que os brasileiros pobres recorriam aos remédios retirados da natureza. Muitos conhecimentos utilizados pelos brancos pobres eram oriundos de seus próprios saberes ancestrais provenientes da Europa, mas que a estes foram incorporados os conhecimentos sobre plantas e suas propriedades medicinais provenientes dos povos afrodescendentes, bem como conhecimentos de plantas medicinais e rituais de cura dos povos indígenas presentes nas regiões colonizadas.

Em muitas cidades do interior do Brasil a prática das benzeduras ainda é muito forte, muitas vezes se recorre à medicina tradicional (médicos, hospitais e remédios alopáticos), mas também se pede auxílio às benzedeiras, que se dedicam a ajudar e curar a população com o auxílio de chás, pomadas, infusões e fé. E isso é uma questão cultural. É importante ter em mente que "cada realidade cultural tem sua lógica interna, a qual devemos procurar conhecer para que façam sentido as suas práticas, costumes, concepções e as transformações pelas quais estas passam" (Santos, 1987: 8).

Após o relato sobre a falta de médicos, Dona Agda demonstra como confecciona uma pomada de alecrim, cachaça e confrei. Segundo ela "muito boa pra dores muscular, dores no joelho, nos pés... (sic)". Por fim, Dona Agda completa, com todo o cuidado: "Benzedeira não é toda pessoa que pode ser. Isso é um dom de Deus (sic)". Segundo as tradições não é qualquer pessoa que pode ser benzedeira ou curador, esse dom normalmente está na família e é repassado entre as gerações. 
Os pássaros cantam, enquanto Dona Agda sai de casa e caminha pelas ruas de chão batido da sua cidade. O vento sopra e uma nova personagem nos é apresentada, Dona Eugênia, que colhe folhas e cipós para produzir juntamente com Dona Agda o chá de "milome". Dona Eugênia colhe plantas medicinais no mato e fala que algumas vezes é necessário recorrer aos remédios de farmácia, pois nem sempre os remédios caseiros fazem efeito. Ela explica sobre a terra e as responsabilidades de cada um que vive no faxinal, onde "ninguém é dono das terras, mas todos são donos (sic)", segundo ela. O cenário bucólico é permeado de imagens de vacas, ovelhas, porcos, carros de boi e homens pescando, a natureza e a tranquilidade da vida do interior são retratadas constantemente no documentário.

O sistema de faxinal é um

modo de utilização das terras em comum, delimitada por cercado, para a criação de animais, existente na região sul do Brasil e que se tem classificado como manifestação cultural dos povos tradicionais. Assim, o faxinal é dividido em terras de criar - ou área de compáscuo -, um cercado composto por matas e pastagens em que se localizam as habitações dos faxinalenses. Na parte interior a essa área comum, que pode pertencer a um proprietário não morador do faxinal ou a vários proprietários, são criados animais de várias espécies, tais como bovinos, equinos, caprinos, ovinos e suínos, além de vários tipos de aves domésticas. Soltos no grande cercado, esses animais alimentamse da grama existente, de pequenos arbustos e dos frutos nativos tais como a gabiroba, a cereja e, principalmente, o pinhão. Os donos dos animais lhes oferecem suplementação alimentar nos períodos de maior escassez. As casas são dispostas no interior da área cercada, sendo boa parte delas protegida por um cercado menor, ao entorno dos quais as criações circulam livremente. As entradas e saídas destas áreas são protegidas por porteiras e cancelas ou por uma espécie de pequenas pontes construídas sobre um vão seco, escavado especialmente para tal fim. Esses artefatos, chamados de mata-burros, são construídos intercalando-se uma prancha e um vão, de modo que as pessoas e os automóveis possam transitar sem a necessidade de abrir porteiras, enquanto que os animais os evitam. As terras de plantar localizam-se fora do cercado e podem pertencer ao proprietário que as cultiva ou serem arrendadas. (Benatte, Campigoto, \& Carvalho, 2011:155).

A Associação Aprendizes da Sabedoria de Medicinais e Agroecologia (ASA) juntamente com a Articulação Puxirão dos Povos de Faxinais mapeou os faxinais do estado do Paraná. O projeto Nova cartografia social dos povos e comunidades tradicionais do Brasil produziu cartilhas com as áreas mapeadas. Os mapas contam com uma legenda detalhada (Figuras 3, 4 e 5), apresentando por meio de imagens informações como: Formas de organização; Ofícios tradicionais; Ervas medicinais dos quintais úteis utilizadas como remédio; Ervas medicinais nativas usadas como remédio; Sementes crioulas; Práticas de pro- 
dução; Práticas tradicionais de cura; Ameaças às práticas e Ofícios tradicionais; Conflitos de acesso e uso dos recursos naturais e Uso da terra.

Figuras 3, 4 e 5. Legenda de mapa dos faxinalenses
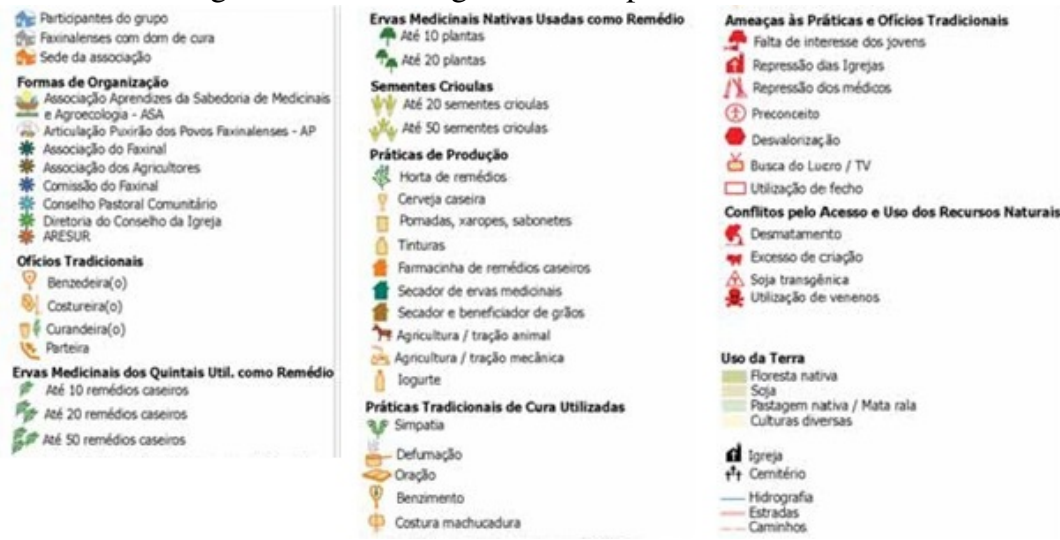

Fonte: Projeto Nova cartografia social dos povos e comunidades tradicionais do Brasil (2008).

Figura 6. Recorte do Mapa do Faxinal Marmeleiro de Cima - Rebouças/PR

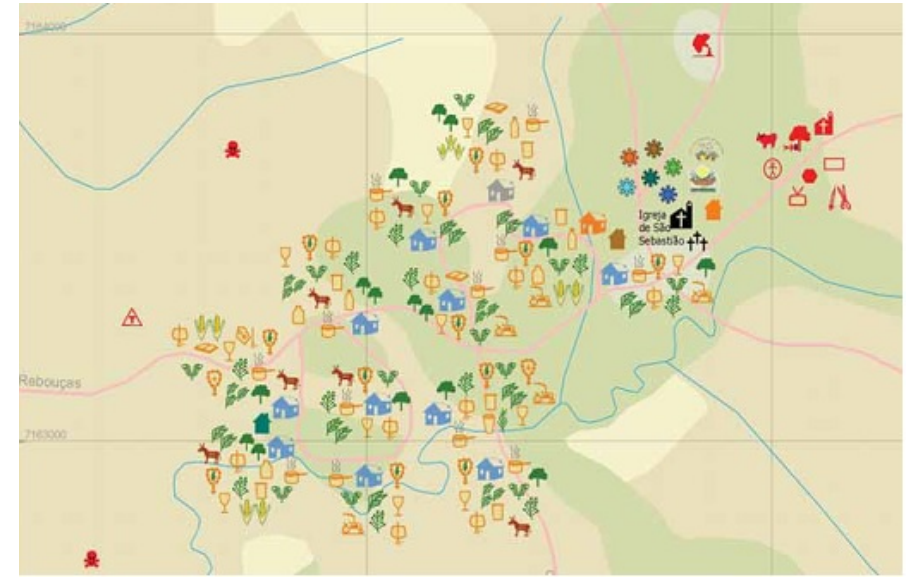

Fonte: Projeto Nova cartografia social dos povos e comunidades tradicionais do Brasil (2008).

O material produzido e divulgado pela Associação Aprendizes da Sabedoria de Medicinais e Agroecologia (ASA) e Articulação Puxirão dos Povos de Faxinais apresenta detalhes de algumas comunidades de faxinais dos municípios de Rebouças, São João do Triunfo e Irati, todas do estado do Paraná. 
Na figura 6, para exemplificar, é possível observar a utilização dos dados da legenda em um recorte do mapa do Faxinal Marmeleiro de Cima, da cidade de Rebouças no Paraná.

A análise do mapa desta região apresenta uma série de ameaças aos recursos naturais das comunidades faxinalenses, tais como o desmatamento das matas nativas, a excessiva utilização de veneno nas plantações de soja que cercam muitos faxinais, bem como a criação em larga escala de animais de corte. Todos esses problemas atrelados à forte repressão das igrejas e dos médicos, aliados ao preconceito e a falta de interesse dos mais jovens impactam diretamente nas atividades das benzedeiras e curandeiros das regiões analisadas.

Toda a tranquilidade reproduzida no documentário é quebrada quando Dona Eugênia traz à tona o assunto "medo". É ela que conta que as benzedeiras tinham muito medo e que por isso um grupo de pessoas se organizou a fim de valorizar os conhecimentos das benzedeiras. Como dito anteriormente, com base nessa organização é que elas (as benzedeiras) passaram a ser valorizadas pelos seus conhecimentos medicinais, tanto por parte dos políticos como da população.

A cineasta Lia Marchi, fala com admiração das personagens do documentário e de sua luta pelo reconhecimento de um ofício tão presente nas comunidades brasileiras, afinal essa luta não é apenas das benzedeiras e curadores do Paraná, mas de pessoas de várias comunidades existentes no Brasil

Eu acho que o movimento que as benzedeiras organizaram, que gerou uma lei que é pioneira no Brasil, que a primeira lei, uma lei municipal de Rebouças, que reconhece a importância dos saberes tradicionais na saúde popular. É uma conquista enorme, eu fico pensando, meu Deus, elas estão lá no interior, muitas delas são senhoras já de alguma idade, e elas tiveram a coragem de lutar para serem reconhecidas, numa coisa que elas fazem que é um bem, que ajuda muito a comunidade. E que eu espero também que a história delas ajude outras comunidades, que precisam ganhar espaço e serem reconhecidas também (sic). (Marchi, 2015).

Dona Donatila aparece com o machado em punho e lentamente a lenha vai sendo cortada, assim como o medo que ela sentia aos poucos foi sendo suplantado pelo fato de finalmente pertencer a um grupo de pessoas que passou a ser reconhecido pelo seu ofício. Donatila, sentada em sua varanda, conta:

Não é todos os padre. Não tudo. É uns. Ele não acredita que, o que é. E o povo denunciam....Denunciam, por que eu fui denunciada. O padre, o padre ia batendo sobre cuidador, ia batendo... Porque, porque isso, porque aquilo... Porque aquilo, porque aquilo, porque é para ganhar dinheiro... Porque isso, porque aquilo. E daí até peguemo a carteirinha. Como diz, agora não tem pobrema nenhum... (sic). 
Os signos icônicos que nos são apresentados no relato de Dona Donatila nos remetem às famosas cenas retratadas nas obras de arte e nas obras ficcionais que abordam a Inquisição, nas quais mulheres eram perseguidas por padres e denunciadas por vizinhos por práticas consideradas como bruxaria. Além disso, os estudos de Benatte; Campigoto e Nascimento (2013: 51) sobre os conhecimentos tradicionais reafirmam que "historicamente, essas práticas foram drasticamente combatidas pela Igreja Católica que as considerava como atividades profanas, relacionadas à bruxaria ou à feitiçaria; mutatis mutandis, o mesmo pode ser dito quanto às práticas afro-brasileiras e africanas".

Retornemos a Dona Agda, que continua caminhando pela pequena cidade. A sua fala compactua com o relato de Dona Donatila, ao dizer:

Nós tinha medo de ser presa, porque muita gente foi preso por causa disso... Você dá um remédio para criança, aí o remédio fazia mal... levavam no médico e o médico mandava buscar preso. Depois que entrou o movimento, que nós tivemo apoio do, do governo, do ministério público de vários lugar lá que deram apoio para nós, fizemo as carteirinha, que nós tivemo a liberdade, se organizemo. O movimento das benzedeira foi criado por pessoas que vieram de fora ensina, explica o que que ia resolve as lei que nós ia tê. Então foi isso aí que começo. Eles iam de cada dois mês a reunião com nós, nós já diferente, entrevistando e daí nos já ia se explicando (sic).

A benzedeira está cruzando o vilarejo. Hoje o medo já não existe mais. E ao olhar para a câmera Dona Agda diz, sorrindo:

É, nós tamo indo convidá as benzedeira por encontro, e eu tô convidando Dona Maria, Dona Ana Catarina, a minha comadre Rose, que vai ser a cozinheira nossa (sic).

Podemos tomar estes momentos descritos por Dona Donatila e por Dona Agda como uma pedagogia da realidade, termo proposto por Beatriz Jaguaribe (2010: 7), que visa compreender "o uso de estéticas realistas em várias modalidades e expressões como meio de ilustrar retratos da realidade contemporânea de uma forma legível para espectadores ou leitores." Segundo Jaguaribe (2010), a pedagogia da realidade nos permite problematizar questões culturais, sociais e individuais. O relato de uma situação de violência, tão comum em nossa sociedade, mas que quando vivenciada por pessoas que buscam trazer apenas um pouco de alívio, conforto, cura e paz para aqueles que as procuram, passa a ser incompreensível.

Em 2008, aconteceu o I Encontro Regional de Rezadeiras, Curadores e Costureiras de machucaduras de cidades do centro-sul do Paraná, organizado pelo Movimento Aprendizes da Sabedoria (Paraná Shop, 2015). Agora, o ôni- 
bus percorre as ruas de terra coletando pessoas para mais um encontro ${ }^{1}$. Enquanto o grupo desembarca, ouvimos mais um relato.

Primeiro eles vieram pra trazê aquela palavra que vai trabaiá dentro daquele resgatando as benzedeira, resgatando a cultura e daí foi reunindo as benzedeira, fizeram um mapeamento, que eles chamavam mapeamento social dentro dos encontro onde tinha muita troca de experiência. Na verdade, não só troca de experiência, como remédio, né? Que eu tinha lá em casa um remédio, eu vinha e eu trocava, como existe até hoje conforme encontro já tem a troca de experiência nas curas mesmo. Trocando experiência ali na hora do almoço, depois do almoço, nos minutinho que tinha e eu fui aprendendo mais e conhecendo mais as planta, né? (sic).

Essa fala é de Dona Ana. O relato de Dona Ana nos apresenta a simplicidade e também nos mostra força de mulheres e homens que apesar de inúmeras adversidades não perderam a fé em ajudar os outros com seus dons; além disso, por meio dos encontros e do reconhecimento que obtiveram passaram a ser um grupo ainda mais forte e homogêneo.

No encontro retratado no documentário, as benzedeiras e os benzedores estão trocando experiências. O quadro negro, da sala que está sendo utilizada para o encontro, está repleto de fotografias e na sua frente estão dispostas plantas medicinais que serão compartilhadas. Os encontros promovidos pela Associação Aprendizes da Sabedoria de Medicinais e Agroecologia (ASA) e Articulação dos Povos Faxinalenses, tem como objetivo:

a) Resgatar e repassar os conhecimentos sobre ofícios tradicionais e ervas medicinais;

b) Lutar junto aos órgãos públicos para construção de Políticas Públicas de reconhecimento e fortalecimento dos ofícios tradicionais e dos remédios caseiros;

c) Construir leis municipais que regulamentem os ofícios tradicionais e os remédios caseiros;

d) Lutar para que a floresta rica em ervas medicinais permaneça livre de qualquer tipo de contaminação e o remédio de livre acesso a toda a população Faxinalense. (Projeto Nova cartografia social dos povos e comunidades tradicionais do Brasil, 2008).

Dona Agda, com toda sua desenvoltura, mais uma vez está à frente, fazendo as apresentações do encontro e chama Michel, que segundo ela é a "primeira raizinha" desse encontro transformador. Michel pergunta quem recorda o lema das benzedeiras e Dona Ana Maria (que não aparece na cena) prontamente responde: "Cuidar da vida é nossa missão!".

1. Encontro de 2015 realizado em Rio Bonito, PR. (Marchi, 2015). 
Agora, as benzedeiras podem mostrar-se sem medo e uma felicidade tranquila toma as cenas finais do documentário quando o grupo está reunido à porta do local do evento, entoando o lema: "Cuidar da vida é nossa missão!". Algumas benzedeiras mostram suas carteirinhas para a equipe.

Figura 7 e 8 . Imagens das benzedeiras exibindo suas carteirinhas
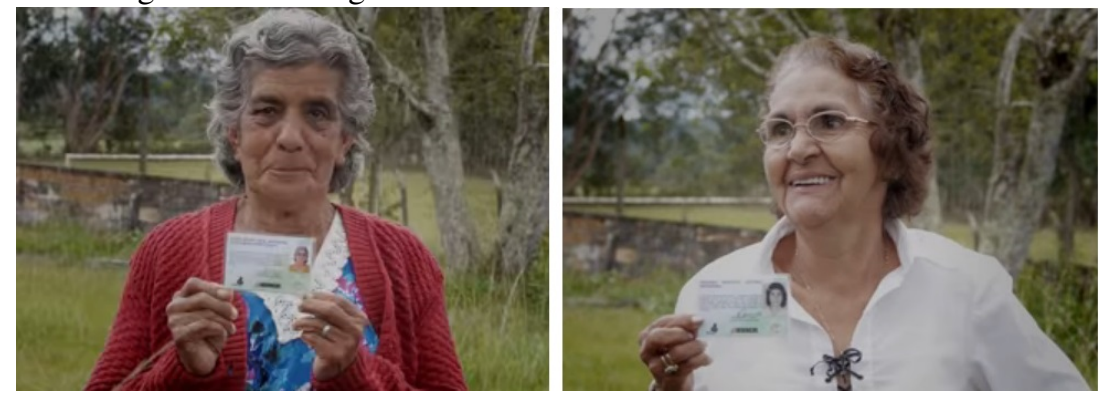

Fonte: Frame capturado do documentário Benzedeiras: ofício tradicional (2015).

\section{Considerações Finais}

O que se pode identificar no meio sorriso dado pelas benzedeiras que mostram sua carteirinha para a câmera? Pode-se dizer que o sentimento representado no olhar e neste meio sorriso que se apresenta é "orgulho"? Orgulho de pertencer a um grupo de indivíduos finalmente reconhecidos pela sociedade? Acredito que sim... é isso que eu posso compreender e captar ao ver aqueles rostos simples, humildes e felizes.

O documentário Benzedeiras: ofício tradicional não trata exclusivamente da questão da utilização dos recursos naturais, apresenta-a de maneira indireta, pois os recursos naturais são fundamentais para o trabalho desenvolvido pelas benzedeiras e demais detentores dos ofícios tradicionais.

A singeleza das escolhas de Lia Marchi ao retratar o cotidiano das benzedeiras, apresentando imagens do seu ofício, relatos, algumas práticas de benzedura, bem como a confecção de chás e pomadas, juntamente com registros de mais um encontro no qual a troca de experiências e de ervas medicinais permitem que o documentário seja transformador, já que, uma vez registradas, as imagens e ações deste grupo de pessoas perdurarão em nossa história, pois como afirma Coutinho (2003: 215) "o documentário é feito para durar". 


\section{Referências}

Benatte, A. P.; Campigoto, J. A. \& Carvalho, R. (2011). Os santos nos faxinais: religiosidade e povos tradicionais. Topoi, 12 (23): 140-160.

Benatte, A. P.; Campigoto, J. A. \& Nascimento, J. J. V. (2013). Povos faxinalenses: saúde e conhecimentos tradicionais. Diálogos, 17 (1): 41-68.

Ferreira, J. P. (1996). Os ofícios tradicionais: cultura é memória. Revista USP, São Paulo, 29: 102-106. Disponível em: http://www.usp.br/revistausp/29 /15-jerusa-pires.pdf

Figuerôa, A.; Bezerra, C. \& Fechine, Y. (2003). O documentário como encontro: entrevista com o cineasta Eduardo Coutinho. Galáxia, (6): 213-229. Disponível em: http://revistas.pucsp.br/index.php/galaxia/article/view/13 $48 / 833$

Jaguaribe, B. (2010). Ficções do real: notas sobre as estéticas do realismo e pedagogias do olhar na América Latina contemporânea. Ciberlegenda, (23): 6-14.

Marchi, L. (s.d.). Benzedeiras - bastidores de gravação. Disponível em: https://www.facebook.com/liamarchioficial/photos/a.925411657502537. 1073741832.848760695167634/925465230830513/?type=3\&permPage

$=>$

Paraná Shop. (s.d.). Documentário revela luta de benzedeiras pelo reconhecimento. Disponível em: http://www.paranashop.com.br/2015/10/docume ntario-revela-luta-de-benzedeiras.html

Projeto Nova Cartografia Social dos Povos e Comunidades tradicionais do Brasil. (2008). Faxinalenses: fé, conhecimentos tradicionais e práticas de cura. Iraty: ASA. Disponível em: http://novacartografiasocial.com/fascic ulos/faxinalenses-sul-brasil/

REDE Católica da Igreja - TV Evangelizar. (s.d.). Jornalismo - Documentário Benzedeiras. Disponível em: https://www.youtube.com/watch?v=J2FpC zyVOXQ

Santos, J. L. (1987). O que é cultura. 6. ed. São Paulo: Brasilense.

\section{Filmografia}

Benzedeiras: ofício tradicional (2015), de Lia Marchi. Disponível em: https://www.youtube.com/watch?v=eBPegB3IIU0 